\title{
Immune responsiveness to phytohemagglutinin displays species but not sex differences in three anuran species
}

\author{
Zhiqiang Zhang ${ }^{\text {Corresp.. }}{ }^{1}$, Chenchen Jin ${ }^{2}$, Kangshan Qu ${ }^{1}$, Enrique Caviedes-Vidal ${ }^{3,4}$ \\ ${ }^{1}$ College of Animal Science and Technology, Anhui Agricultural University, Hefei, People's Republic of China \\ 2 College of Life Science, Anhui Agricultural University, Hefei, People's Republic of China \\ 3 Instituto Multidisciplinario de Investigaciones Biológicas de San Luis, Consejo Nacional de Investigaciones Científicas y Técnicas, and Departamento de \\ Bioquímica y Ciencias Biológicas, Universidad Nacional de San Luis, San Luis, Argentina \\ 4 Department of Forest and Wildlife Ecology, University of Wisconsin-Madison, Madison, United States
}

Corresponding Author: Zhiqiang Zhang

Email address: zzq-003@163.com

Phytohemagglutinin (PHA)-induced skin swelling response is widely used as a rough surrogate of integrative cell-mediated and innate immunity across multiple vertebrate taxa due to its simplification and feasibility. However, little is known whether there are sex and interspecific differences of immune responsiveness to PHA in ectotherms, especially for anurans. Therefore, we studied sex and species differences of PHA response in three anurans, Asiatic toads (Bufo gargarizans), Dark-spotted frogs (Pelophylax nigromaculatus) and Mongolian toads (Pseudepidalea raddei), captured in northern regions of Anhui Province (China). Footpad thickness was measured prior to $(0 \mathrm{~h})$ and after $(6,12,24,48$ and $72 \mathrm{~h}$ ) a PHA injection and normalized against saline injection in the opposite footpad. Body mass was recorded at the beginning $(0 \mathrm{~h})$ and end of each assay (72 h). Results showed effects of PHA assay, sex and taxa on body mass. Relative maximum swelling response $\left(\mathrm{PHA}_{\max }\right)$ ranged from 18.58 to $29.75 \%, 9.77$ to $20.56 \%$ and 21.97 to $31.78 \%$ and its occurrence over time was apparent 10.6 to $19.72 \mathrm{~h}, 7.74$ to $14.01 \mathrm{~h}$ and 17.39 to $23.94 \mathrm{~h}$ postinjection for Asiatic toads, Dark-spotted frogs and Mongolian toads, respectively. Finally, the magnitude or timing of $\mathrm{PHA}_{\max }$ in Dark-spotted frogs was significantly thinner and faster than in Mongolian toads, and Asiatic toads had an inbetween value, not different from the other two species. The magnitude of $\mathrm{PHA}_{\max }$ was significantly positively correlated with the timing of $\mathrm{PHA}_{\max }$ considering individuals altogether, but not when analyzed within species. Our results indicate that male and female anuran species respond similarly to PHA antigen stimulation, but the magnitude and timing of $\mathrm{PHA}_{\max }$ is species-specific. Briefly, we provide new evidence for the suitability of PHA assay in non-model anuran species with different body sizes, and exhort the need to further investigate the nature of PHA assay at the hematological and histological levels in order to extend its application in ecoimmunological studies of amphibians. 
1 Immune responsiveness to phytohemagglutinin displays species but not sex

2 differences in three anuran species

3 Zhiqiang Zhang ${ }^{1 *}$, Chenchen $\mathrm{Jin}^{2}$, Kangshan $\mathrm{Qu}^{1}$ and Enrique Caviedes-Vidal ${ }^{3,4}$

$4{ }^{1}$ College of Animal Science and Technology, Anhui Agricultural University, Hefei, People's Republic of China

$5 \quad{ }^{2}$ College of Life Science, Anhui Agricultural University, Hefei, People's Republic of China

$6 \quad{ }^{3}$ Instituto Multidisciplinario de Investigaciones Biológicas de San Luis, Consejo Nacional de Investigaciones

7 Científicas y Técnicas, and Departamento de Bioquímica y Ciencias Biológicas, Universidad Nacional de San

8 Luis, San Luis, Argentina

$9 \quad{ }^{4}$ Department of Forest and Wildlife Ecology, University of Wisconsin-Madison, Madison, United States

10 Short title: Sex and species changes of PHA response

11 Correspondence: Zhiqiang Zhang, College of Animal Science and Technology, Anhui

12 Agricultural University, 130 Changjiang West Road, Shushan District, Hefei 230036, People's

13 Republic of China.

14 Email: zzq-003@163.com

15 ABSTRACT

16 Phytohemagglutinin (PHA)-induced skin swelling response is widely used as a rough surrogate

17 of integrative cell-mediated and innate immunity across multiple vertebrate taxa due to its 
18 simplification and feasibility. However, little is known whether there are sex and interspecific

19 differences of immune responsiveness to PHA in ectotherms, especially for anurans. Therefore,

20 we studied sex and species differences of PHA response in three anurans, Asiatic toads (Bufo

21 gargarizans), Dark-spotted frogs (Pelophylax nigromaculatus) and Mongolian toads

22 (Pseudepidalea raddei), captured in northern regions of Anhui Province (China). Footpad

23 thickness was measured prior to $(0 \mathrm{~h})$ and after $(6,12,24,48$ and $72 \mathrm{~h})$ a PHA injection and

24 normalized against saline injection in the opposite footpad. Body mass was recorded at the

25 beginning $(0 \mathrm{~h})$ and end of each assay $(72 \mathrm{~h})$. Results showed effects of PHA assay, sex and taxa

26 on body mass. Relative maximum swelling response $\left(\mathrm{PHA}_{\max }\right)$ ranged from 18.58 to $29.75 \%$,

279.77 to $20.56 \%$ and 21.97 to $31.78 \%$ and its occurrence over time was apparent 10.6 to $19.72 \mathrm{~h}$,

287.74 to $14.01 \mathrm{~h}$ and 17.39 to $23.94 \mathrm{~h}$ postinjection for Asiatic toads, Dark-spotted frogs and

29 Mongolian toads, respectively. Finally, the magnitude or timing of PHA $\max$ in Dark-spotted frogs

30 was significantly thinner and faster than in Mongolian toads, and Asiatic toads had an in-between

31 value, not different from the other two species. The magnitude of $\mathrm{PHA}_{\max }$ was significantly

32 positively correlated with the timing of $\mathrm{PHA}_{\max }$ considering individuals altogether, but not when

33 analyzed within species. Our results indicate that male and female anuran species respond

34 similarly to PHA antigen stimulation, but the magnitude and timing of $\mathrm{PHA}_{\max }$ is species-specific.

35 Briefly, we provide new evidence for the suitability of PHA assay in non-model anuran species

36 with different body sizes, and exhort the need to further investigate the nature of PHA assay at

37 the hematological and histological levels in order to extend its application in ecoimmunological

38 studies of amphibians.

39 INTRODUCTION

40 Amphibians are experiencing a global biodiversity crisis derived from diseases, habitat

41 destruction and altered ecosystems (Clulow, Harris \& Mahony, 2015). A wide range of

42 physiological traits including innate and adaptive immunity are important to cope with the 
increasing number of stressors and pathogen threats faced in their lifetimes (Carey, Cohen \& Rollins-Smith, 1999). As other physiological traits, immune defense is also energetically costly to mount, and a trade-off relationship may occur within the immune system or between immunological defenses and other nutrient-demanding processes such as growth, reproduction and thermoregulation based on limited total energy resources (Lochmiller \& Deerenberg, 2000). Nowadays, it is still an open question what immune parameter measures are appropriate to reflect an organism's defense capacity against pathogens (Downs, Adelman \& Demes, 2014). Among several immunological assays, the phytohemagglutinin (PHA) skin-swelling test is one of the most widely used techniques to evaluate the magnitude of vertebrate immune response (Sheldon \& Verhulst, 1996; Boughton, Joop \& Armitage, 2011; Vinkler \& Albrecht, 2011; Brock, Murdock $\&$ Martin, 2014). The assay consists of a subcutaneous injection of PHA that induces infiltration of leukocytes and where swelling is interpreted as an integrative immune response (Christe, Arlettaz \& Vogel, 2000; Kennedy \& Nager, 2006; Martin et al., 2006; Demas et al., 2011; Brock, Murdock \& Martin, 2014) or as an inflammation in endotherms (Vinkler et al., 2012; Bílková, Vinklerová \& Vinkler, 2015; Bílková et al., 2016). However, inferences using this assay should be carefully evaluated because not always a greater immune response or inflammation means better defenses against infections or higher survival probabilities (Graham, Allen \& Read, 2005; Vinkler et al., 2012). To date, the histological base of this response has been demonstrated across different vertebrate taxa [e.g., birds (Martin et al., 2006), bats (Turmelle et al., 2010), amphibians (Brown, Shilton \& Shine, 2011) and crocodiles (Finger et al., 2013)], although no apparent correlation between swelling response and leukocyte profiles was reported in the fossorial mammal Ctenomys talarum (Merlo, Cutrera \& Zenuto, 2014). However, more recently PHA swelling has been associated to leukocyte profiles and serum bactericidal activity in endotherms (Bilková, Vinklerová \& Vinkler, 2015; Zhang \& Zhao, 2015), or parasite infection in rodents (Ctenomys talarum, Merlo, Cutrera \& Zenuto, 2015). Despite all the merits of this assay, a caveat 
must be warned because there is still some debate about its meaning. An objection is that the response to PHA of an organism might not be representative of the actual response of the same host to pathogens (reviewed by Graham, Allen \& Read, 2005; Owen \& Clayton, 2007; Brock, Murdock \& Martin, 2014) or that energetic costs of mounting a response to PHA may vary in small mammals (Zhang, Qiu \& Wang, 2011; Merlo et al., 2014) and birds (Ots et al., 2001; Martin, Scheuerlein \& Wikelski, 2003; Lee, Martin \& Wikelski, 2005; Nilsson, Granbom \& Råberg, 2007).

PHA assay was first used in ecoimmunological studies of amphibians in the northern leopard frogs, Rana pipiens, showing noticeable alterations of the immune response after an exposure to different pesticides (Gilbertson et al., 2003). The sites chosen to inject PHA are diverse for postmetamorphic amphibians and none is applicable to all species, for example, toe webbing (Brown, Shilton \& Shine, 2011), footpad (Fites et al., 2014), thigh (Gervasi \& Foufopoulos, 2008) and lower leg below the knee (Clulow, Harris \& Mahony, 2015). The histological mechanism of the inflammatory response induced by PHA antigen was examined in the toe webbing of cane toads, Rhinella marinus (Brown, Shilton \& Shine, 2011), which displayed a rapid $(<12 \mathrm{~h})$ infiltration of neutrophils, eosinophils and macrophages at the injection site, followed by an influx of lymphocytes by $24 \mathrm{~h}$ postinjection. In addition, marked interspecific variations of leukocytes were observed in the lower leg of green and golden bell frogs, Litoria aurea and striped marsh frogs, Limnodynastes Peronii (Clulow, Harris \& Mahony, 2015). PHA assay has been also used to assess the immune responsiveness under different ecologically relevant conditions, such as when amphibians are forced to accelerate the metamorphosis by exposition to environment desiccation (Gervasi \& Foufopoulos, 2008), treated with protein restricted diets (Venesky et al., 2012), and exposed to density stress (Clulow, Harris \& Mahony, 2015). In different vertebrate species, PHA response peaks in a wide time window, from 3 to $48 \mathrm{~h}$ (de Bellocq et al., 2006; Martin et al., 2006; Turmelle et al., 2010; Xu \& Wang, 2010; Brown, Shilton \& Shine, 2011; 
93 Finger et al., 2013; Josserand et al., 2015; Zhang, Huang \& Zhao, 2015; Bílková et al., 2016),

94 with no apparent sex differences in some small mammals (Zhang, Qiu \& Wang, 2011; Merlo,

95 Cutrera \& Zenuto, 2014) and amphibians (Brown et al., 2015; Clulow, Harris \& Mahony, 2015).

96 Most up-to-date information available on the time course and temporal dynamics of the PHA

97 responses within and among populations or species are for birds (Navarro et al., 2003) and small

98 mammals (de Bellocq et al., 2006; Zhang, Huang \& Zhao, 2015). Conversely, data on

99 amphibians are still scarce, especially for those anurans living in different environments (Clulow,

100 Harris \& Mahony, 2015). In a scenario of increasing disease and toxic threats, it is mandatory the

101 need to provide comparable information of individual health status induced by PHA antigen on

102 key amphibian species (Carey, Cohen \& Rollins-Smith, 1999; Fites et al., 2014; Clulow, Harris

$103 \&$ Mahony, 2015).

104 In line with this situation, our aim was to test PHA assay response across different species with

105 different body masses to extend its use to other non-model anuran species with different

106 morphological and physiological adaptations to their habitats. Accordingly, we provide an

107 evaluation of the PHA-induced skin-swelling assay among three sympatric anuran species with

108 different habitat use in a range of body mass (30 to $90 \mathrm{~g}$ ) of Central China (Northern Anhui

109 province), Dark-spotted frogs (Pelophylax nigromaculatus), Mongolian toads (Pseudepidalea

110 raddei) and Asiatic toads (Bufo gargarizans). In the three anuran species, both Asiatic and

111 Mongolian toads are terrestrial with slow movements, whereas Dark-spotted frogs dwell lentic

112 ponds or rice fields and move fast in their habitats (Fei et al., 2009a, b). In addition, Asiatic toads

113 start their reproductive activities during hibernation ( $\mathrm{Ji}$ et al., 1995; Zou et al., 1996) and are

114 easily infected by multiple parasites (Zhao et al., 2014). On the other side, while Mongolian toads

115 (Zhou, 1996) and Dark-spotted frogs initiate their reproduction after hibernation ( $\mathrm{Wu}, 1965 ; \mathrm{CaO}$

116 et al., 1996; Jin, Qu \& Zhang, 2014; Jin \& Zhang, 2014), the former is not infected by multiple

117 digenetic trematodes $(L i \& G u, 1978)$, but the latter, displays a $90.38 \%$ helminth and parasite 
118 infection rate (Zhu et al., 2014). We predicted that: (i) Within species, both sexes will exhibit

119 similar swelling responses. (ii) The temporal dynamics of the response to PHA will be species-

120 specific, as well as the magnitude of the maximum swelling at the injection point in the footpad

121 area. In addition, we tested the effect of the PHA assay on the body mass of the individuals and

122 its influence on the swelling response.

123 MATERIALS AND METHODS

124 Animal husbandry

125 All animal procedures were carried out under the guidelines of the Animal Care and Use 126 Committee of Anhui Agricultural University (Permit number: 20120410). During April and May, 127 2012, we captured nine and eight males and nine and ten females Asiatic and Mongolian toads, 128 respectively, in Mengcheng county $\left(116.55^{\circ} \mathrm{E} 33.25^{\circ} \mathrm{N}\right.$ Anhui province, China), and eight males 129 and eight females of Dark-spotted frogs in Feixi county $\left(117.17^{\circ} \mathrm{E} 31.70^{\circ} \mathrm{N}\right.$ Anhui province, 130 China). Immediately after capture, animals were transported to an animal indoor facility of the 131 Anhui Agricultural University in Hefei, and housed in aquarium tanks $(40 \times 50 \times 90 \mathrm{~cm})$. They 132 were kept under natural ambient temperature $\left(17-21^{\circ} \mathrm{C}\right)$ and photoperiod (around 12L:12D). 133 Fresh dechlorinated tap water was provided ad libitum and mealworms were provided as their 134 food every 2-3 days during trials.

\section{PHA-induced skin-swelling test}

In all cases PHA-induced skin-swelling responses were always assayed two or three days after capture. Animals were subcutaneously injected with a dose of $50 \mu 1$ of the PHA solution (PHA-P, Sigma L-8754, Sigma-Aldrich, St Louis, MO, USA, $1 \mathrm{mg}$ of PHA-P dissolved in $0.3 \mathrm{~mL}$ of saline solution) in the footpad area pointing to the junction of the second and third digits of the right hind foot, and the opposite left footpad as an intragroup control was injected with an equal volume of sterilized saline by using a $100 \mu \mathrm{l}$ micro injector (Shanghai Anxiang micro injector factory, China). Footpad thickness was measured with a micrometer (Tesa Shopcal, Renens, 
143 Switzerland) to $\pm 0.01 \mathrm{~mm}$, prior to injection (time $=0 \mathrm{~h}$ ), and then at $6,12,24,48$ and $72 \mathrm{~h}$

144 postinjection. Footpad thickness was measured six times at each time point by the same operator 145 at the point of injection and the average value was used for analysis (Smits, Bortolotti \& Tella, 146 1999; de Bellocq et al., 2006). Body mass ( $\pm 0.001 \mathrm{~g})$ was recorded at time $0 \mathrm{~h}$ and then, $72 \mathrm{~h}$ 147 after injection in each individual of each species. In order to minimize measurement biases due to 148 different initial footpad thickness, the expressed percentages of PHA-induced swelling responses 149 (\%) were calculated as described by Brown et al. (2015) for cane toads (Rhinella marina).

$100 * \frac{\text { PHA thickn ess at } \mathrm{x} \text { hour }-\mathrm{PHA} \text { thickn ess at } 0 \text { hour }}{\text { PHA thickn ess at } 0 \text { hour }}-\frac{\text { Saline thickness at } \mathrm{x} \text { hour }- \text { Saline thickness at } 0 \text { hour }}{\text { Saline thickness at } 0 \text { hour }}$

\section{Statistics}

Data are presented as means \pm 1 SEM. Each measurement of PHA swelling response was replicated six times. A very high repeatability of these measurements was observed using intraclass correlation coefficients $(r=0.99, P<0.001)$. Therefore, hereafter the mean value of the six measurements of the swelling response for each individual was used for analyses.

Differences among group means were analyzed using analyses of the variance and covariance. Assumptions of ANOVAs and ANCOVAs were tested and when no met, the nonparametric Kruskal-Wallis H test was used. Tukey's HSD test was carried out to evaluate pairwise comparisons after ANOVAs, and Dunn's multiple comparisons test was performed after KruskalWallis H. Species, sex and PHA assay effects on body mass were evaluated using a mixed-design ANOVA with an autoregressive (order 1) covariance structure (Littell, Pendergast \& Natarajan, 2000) including pre and post-assay body masses, sex and species as fixed factors and subjects nested in sex and species as random factors. A mixed-design ANOVA with an autoregressive 
163 (order 1) covariance structure was performed to test differences within individuals of the swelling 164 response at different times $(6,12,24,48$ and $72 \mathrm{~h})$ after the PHA injection in the three species 165 studied, using time after injection and sex as fixed factors and subjects nested in sex as a random 166 factor. The maximum skin swelling response $\left(\mathrm{PHA}_{\max }\right)$ after the PHA injection of an individual 167 was defined as the highest of the five values measured along trial time (i.e., 6, 12, 24, 48 and 72 variables. h), and the time when $\mathrm{PHA}_{\max }$ was reached, as the time of peak. $\mathrm{PHA}_{\max }$ was contrasted among the three species using an ANOVA, using full factorial design with taxa and sex as predictor

Likelihood comparisons of the Akaike Information Criterion $\left(\mathrm{AIC}_{\mathrm{c}}\right)$ with a second-order bias correction values produced by models using different parameters (i.e., time-after PHA injection and sex as variables and mean body mass as a covariate) for the different species studied were used as tool to select the predictors that described the best model for PHA swelling response within species (Burnham \& Anderson, 2004). Using this procedure, variables included in the models were time-after PHA injection and sex. The same process was used to select the predictor variables, taxa and sex, to analyze $\mathrm{PHA}_{\max }$. Since times of peak and transformed values did not meet the normality assumption (D'Agostino's $K^{2}$ test, $P<0.05$ ), a Kruskal-Wallis $\mathrm{H}$ test was used to test differences among taxa and sex. The correlation between PHA max $_{\text {and }}$ aning of the peak was analyzed using the Spearman's rank correlation coefficient. In all tests, statistical significance was accepted for $\alpha<0.05$. Statistical analyses were performed using JMP Pro 12.2.1.

\section{RESULTS}

\section{Effects of PHA test, sex and species on body mass}

A mixed-design ANOVA was conducted to test PHA assay effect on body mass in male and female individuals of the three species studied. Results showed significant body mass pre- and 72 h post- PHA injection changes within subjects (Table 1). Pairwise comparisons showed that all 
188 effects (i.e. sex and taxa) and all interactions were statistically significant (Table 1). Sex 189 differences of body mass before the assay were apparent for Asiatic toads, while Dark-spotted 190 frogs and Mongolian toads did not differ. After the assay, body mass differed significantly 191 between sexes in all species (Fig. 1). Body mass differences between taxa were also apparent, 192 Dark-spotted frogs were lighter than Mongolian toads and Asiatic toad males, and in turn, lighter 193 than the females of Asiatic toads (Fig. 1).

194 Table 1. Results of a full factorial mixed-design ANOVA with an autoregressive (order 1)

195 covariance structure (Littell, Pendergast \& Natarajan, 2000) run to test changes within subjects 196 of the body mass before and after the PHA test using assay, sex and taxa as fixed factors and the 197 subjects nested in sex and taxa as random factors.

\begin{tabular}{lccc}
\hline \multicolumn{1}{c}{ Source } & $\boldsymbol{d . f}$. & $\boldsymbol{F}$ & $\boldsymbol{P}$ \\
\hline Assay & $1,43.3$ & 146.952 & $<0.0001$ \\
Sex & 1,44 & 7.876 & 0.0074 \\
Taxa & $2,43.9$ & 83.365 & $<0.0001$ \\
Sex x assay & $1,43.6$ & 8.767 & 0.0049 \\
Sex x taxa & $2,43.9$ & 13.683 & $<0.0001$ \\
Taxa x time & $2,43.4$ & 13.107 & $<0.0001$ \\
Sex x taxa x & $2,43.5$ & 4.988 & 0.0112 \\
& & & \\
assay & & & \\
\hline
\end{tabular}




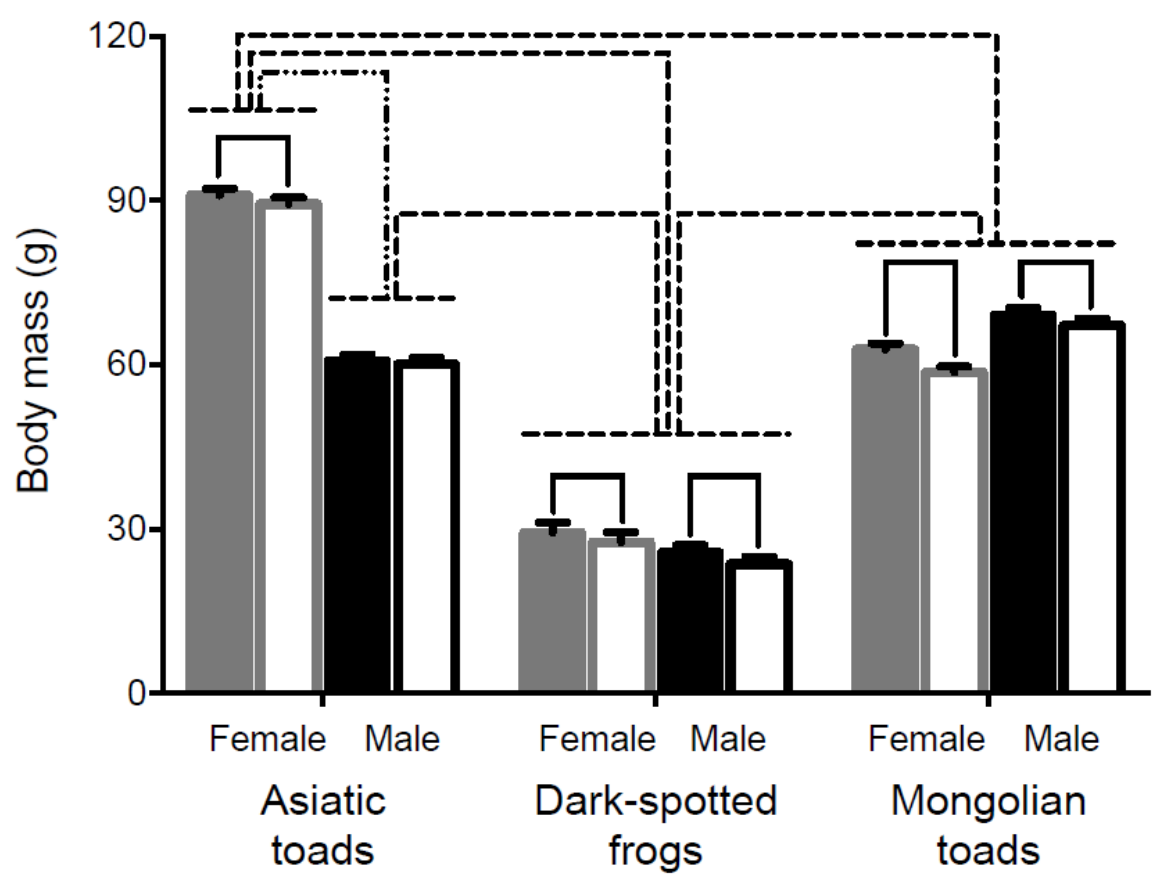

Figure 1. Effects of the phytohemagglutinin (PHA) assay, sex and taxa on body mass in the three anuran species studied, Asiatic toads, Dark-spotted frogs and Mongolian toads. Bars represent mean body mass \pm 1 S.E.M. Body masses of female and male individuals of each species before the PHA injections are represented by solid gray and black bars respectively, and $72 \mathrm{~h}$ postinjection body masses of females and males are represented by unfilled gray and black bars, respectively. Bars or groups of bars connected by either solid (pre vs. post PHA injection), dashed-double-dot (sex) or dashed (species) lines indicate significant differences of body masses by Tukey's HSD test $(P<0.05)$.

\section{PHA-induced skin swelling response}

Skin swelling response after PHA injection showed significant differences within individuals of the three species studied (Table 2, Ps $<0.0001$ ). All species increased the thickness of the footpad area following the PHA injection reaching a maximum skin swelling response (Tukey's HSD test, $P<0.05)$ and then the swelling significantly declined to a minimum at $72 \mathrm{~h}$ (Fig. 2). A closer 
211 inspection of $\mathrm{PHA}_{\max }$ and its occurrence over time (Fig. 3) showed that both parameters varied 212 within species: the $95 \% \mathrm{CI}$ of $\mathrm{PHA}_{\max }$ and times of peak ranged from 18.58 to $29.75 \%$ and 10.6 213 to $19.72 \mathrm{~h}, 9.766$ to $20.56 \%$ and 7.738 to $14.01 \mathrm{~h}$, and 21.97 to $31.78 \%$ and 17.39 to $23.94 \mathrm{~h}$ for 214 Asiatic toads, Dark-spotted frogs and Mongolian toads, respectively. Sex effect or interaction 215 time x sex were not significant in the three species (Table 2). Between species differences in the 216 magnitude of $\mathrm{PHA}_{\max }$ were significant (ANOVA, taxa effect: $F_{2,49}=4.1664 ; P<0.022$, Fig. 3A), 217 but not for $\operatorname{sex}\left(F_{1,49}=0.4994 ; P=0.484\right)$ or taxa x sex interaction $\left(F_{1,49}=0.6600, P=0.522\right)$. 218 Tukey's HSD test showed that maximum PHA-induced swelling response of Dark-spotted frogs 219 was significantly thinner than that of Mongolian toads, and Asiatic toads PHA $_{\max }$ was not 220

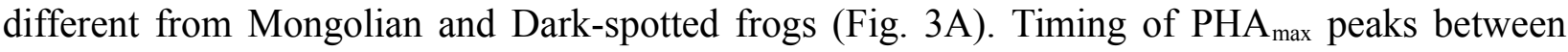
species was also statistically significant (Kruskal-Wallis test: $H_{2}=12.2179, P=0.0022$, Fig. 3B) with score means of 23.33, 17.5 and 33.89 for Asiatic toads, Dark-spotted frogs and Mongolian toads, respectively. Dunn's multiple comparisons test showed that Dark-spotted frogs reached PHA $_{\text {max }}$ significantly faster than Mongolian toads, and Asiatic toads had an in-between value, not different from any of the other two species (Fig. 3B). The relationship between PHA $_{\max }$ and timing of the peak between data of all individuals was significant (Spearman's rank correlation coefficient, $\rho=0.327, P<0.05)$, but we fail to find a significant correlation $(P>0.05)$ within species with or without sex as a category.

Table 2. A full factorial mixed-design ANOVA with an autoregressive (order 1) covariance structure (Littell, Pendergast \& Natarajan, 2000) was run to test changes of the swelling response after the PHA injection using time after PHA injection, sex and taxa as fixed factors, and the 
232 subjects nested in sex and taxa as random factors. Sex and taxa were included as predictor

233 variables and body mass excluded as a covariate based on likelihood comparisons of AICc of the 234 different models (Burnham \& Anderson, 2004).

\begin{tabular}{lllllllllll}
\hline Species & \multicolumn{3}{l}{ time after PHA injection } & \multicolumn{3}{c}{ sex } & \multicolumn{3}{c}{ time x sex } \\
\cline { 2 - 11 } & d.f. & $F$ & $P$ & d.f. & $F$ & $P$ & d.f. & $F$ & $P$ \\
Asiatic toads & $4,53.5$ & 11.42 & $<0.0001$ & $1,54.4$ & 1.07 & 0.306 & $4,53.9$ & 0.49 & 0.746 \\
Dark-spotted frogs & $4,37.9$ & 8.18 & $<0.0001$ & $1,14.7$ & 1.69 & 0.214 & 4,39 & 1.92 & 0.127 \\
Mongolian toads & 4,46 & 31.80 & $<0.0001$ & $1,38.9$ & 0.21 & 0.651 & $4,46.5$ & 1.41 & 0.246 \\
\hline
\end{tabular}




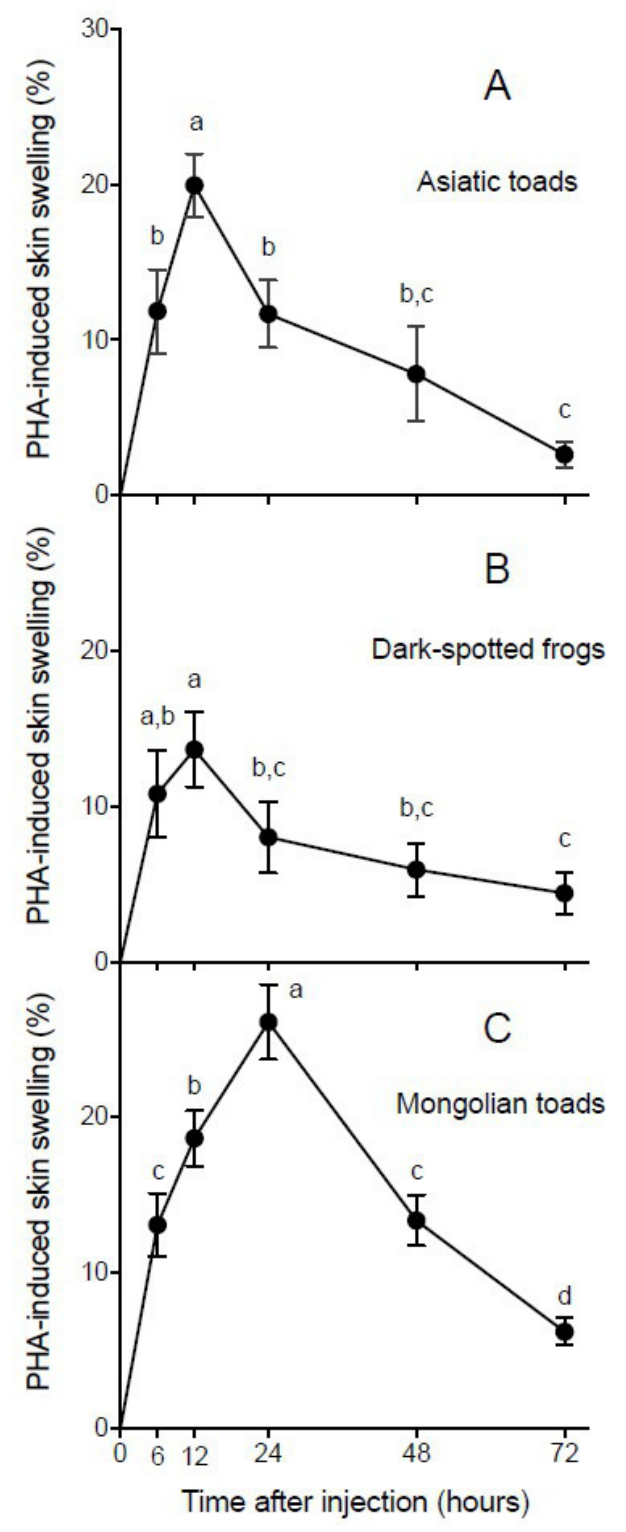

Figure 2. Mean ( \pm 1 S.E.M.) phytohemagglutinin (PHA)-induced skin swelling response, expressed as the percentage of the initial footpad area thickness corrected by the swelling that produce an injection of the same amount of saline solution in the left footpad (see Materials and methods), at 6, 12, 24, 48 and $72 \mathrm{~h}$ after PHA injections in Asiatic toads (A), Dark-spotted frogs (B) and Mongolian toads (C). Points not connected by the same lower case letter are significantly different (Tukey's HSD test, $P<0.05$ ). 

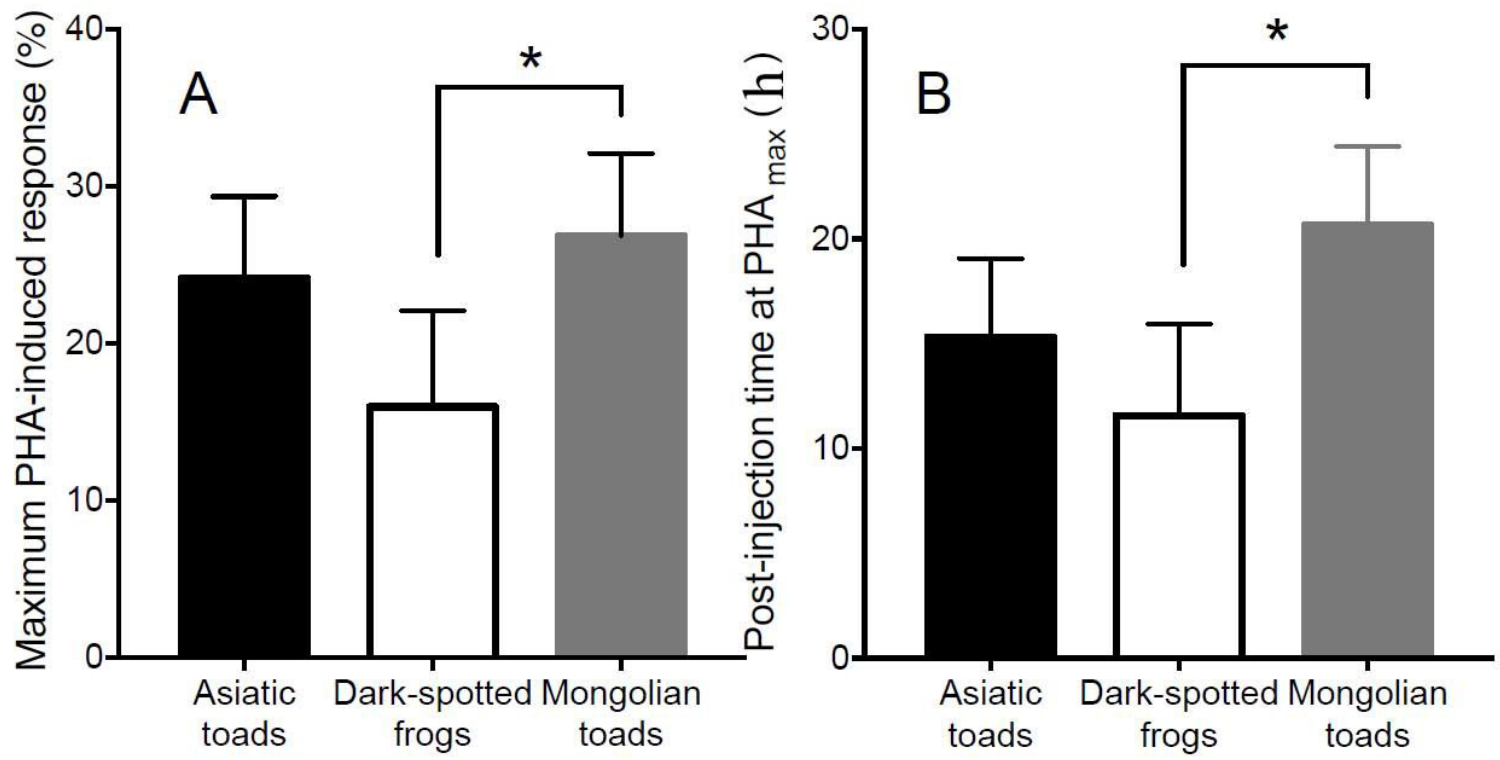

Figure 3. Mean values $\pm 95 \%$ C.I. of (A) maximum phytohemagglutinin-induced skin swelling response $\left(\mathrm{PHA}_{\max }\right)$ and $(\mathrm{B})$ the times of peak of Asiatic toads, Dark-spotted frogs and Mongolian toads. Bars connected by brackets are significantly different $(P<0.05)$ by Tukey's HSD test and Dunn's multiple comparisons test in (A) and (B), respectively.

\section{DISCUSSION}

Consistent with our predictions, male and female anurans responded similarly to PHA (Table 2), suggesting that PHA assay can be used as an effective index for measuring intra-population variations in immune functions within either sex. In addition, PHA assay as an integrative response is comparable in ecoimmunological studies of amphibians with different body sizes, early or delayed primary $\mathrm{PHA}_{\max }$ may match with their reproductive activities and parasite infections from outdoor environmental conditions.

Effects of the PHA assay, sex and taxa on body mass were marked in the three anuran species (Table 1). All groups except for Asiatic toad males lost body mass after the PHA assay (Fig. 1), suggesting that it is necessary to measure their body masses at least prior to injection (at $0 \mathrm{~h}$ ) and 
at $72 \mathrm{~h}$ postinjection. Compared with the toe webbing of large-bodied cane toads (Brown, Shilton $\&$ Shine, 2011) and the lower leg below the knee of several small-bodied tree frogs (Clulow, Harris \& Mahony, 2015), the footpad site injected also displayed a measurable inflammation response after PHA antigen injection, which can be further applied to other anuran species with body sizes in a range of at least 30 to $90 \mathrm{~g}$. As suggested from bird (Smits, Bortolotti \& Tella, 1999) and later from amphibian (Josserand et al., 2015) studies on PHA measurement, a more simplified protocol without saline injection should be considered in future research in amphibians.

In the present study, no sex differences were found for immune responsiveness to PHA in the three anuran species (Table 2, Fig. 2). Similar results had been recorded in chinstrap penguins, Pygoscelis antartica (Moreno et al., 1998), wild rodent species (Zhang, Qiu \& Wang, 2011; Merlo, Cutrera \& Zenuto, 2014), and several anuran species (Brown et al., 2015; Clulow, Harris $\&$ Mahony, 2015). The PHA inflammation assay uses a lectin to elicit localized inflammation that reflects an organism's capacity to mount a dynamic innate and cell-mediated immune response. In a wild rodent, immune responsiveness to primary PHA was positively correlated with the proportion of neutrophils and serum bactericidal capacity in circulating blood (Zhang \& Zhao, 2015), and the energetic cost of mounting this response was low (Zhang, Qiu \& Wang, 2011; Merlo et al., 2014). In amphibians, the primary PHA injection may mainly involve innate phagocytes and granulocytes, and a second PHA injection would strongly activate lymphocytes (Brown, Shilton \& Shine, 2011; Fites et al., 2014; Josserand et al., 2015). In the present study, the activation of the innate immunity induced by a single dose of PHA antigen may represents male and female anurans responses to cope with infectious diseases and changing environmental conditions. During April and May, Asiatic toads almost terminated their reproductive activities (Ji et al., 1995; Zou et al., 1996), whereas Mongolian toads (Zhou, 1996) and Dark-spotted frogs just initiated their reproductive activities (Wu, 1965; Cao et al., 1996; Jin, Qu \& Zhang, 2014; Jin 
$\&$ Zhang, 2014). Male serum testosterone concentrations are higher during the reproductive than in the non-reproductive period in Dark-spotted frogs $(\mathrm{Hu}, 1990)$, or before reproduction than after reproduction in Asiatic toads $(H u, 1989)$. Based in life history theory, it can be hypothesized that males may show a reduced immune response and an increased susceptibility to disease than females due to the suppressive effects of androgens on the immune system (Zuk \& McKean, 1996). Hence, a suppression or at least a reduction of male immune responses is a reasonable prediction if a trade-off relationship exists between immunity and reproduction (Lochmiller \& Deerenberg, 2000). Moreover, male anurans might face a greater risk exposed to more infectious diseases than females because they need croak and move to find a mate during reproduction, which is energetically costly too (Hawley \& Altize, 2011). Strikingly in this study, despite the different reproductive status, vocal and locomotor activity, no apparent dissimilarities were found between male and female anurans in the immune responsiveness pattern to PHA (Fig. 2). Sex differences in immune functions may be associated to the immunological parameters (Boughton, Joop \& Armitage, 2011; Downs, Adelman \& Demes, 2014) or vertebrate life history characters involved (Stoehr \& Kokko, 2006). For example, semi-terrestrial salamanders, Desmognathus ochrophaeus females were reported to heal slower than males from an experimental cutaneous wound, used as a measure of an integrative immune response, and the difference in healing time was related to potential energetic constraints (Thomas \& Woodley, 2015). However, it has also described that Bufo americanus females and larger males display similar proportions of heterophils acting as first-line defenses against bacterial infection in their leukocyte profiles (Forbes, McRue \& Shutler, 2006).

In a range from fast to slow life span rodents, empirical evidences show that different components of the immune system might display similar or different changing tendencies (Martin, Hasselquist \& Wikelski, 2006; Martin, Weil \& Nelson, 2007; Previtali et al., 2012). As an integrative response, the temporal patterns of the PHA response might change in different 
305 rodents, and individuals that responded faster had a lower maximum response than those with a 306 more delayed response (de Bellocq et al., 2006). In twelve Lark species, environmental proxies of 307 antigen exposure explained variation in immune investment better than proxies of pace of life 308 (Horrocks et al., 2015). In anurans, unlike endotherms and regardless of body size, the primary 309 response to PHA antigen injections is mainly attributed to innate immunity of immune system 310 and recognized as the first-line defense to outdoor pathogens (Brown, Shilton \& Shine, 2011; 311 Josserand et al., 2015). The interspecific differences of the magnitude or timing of PHA $\mathrm{max}_{\operatorname{mere}}$ 312 observed in the three anuran species (Table 2, Fig. 3), suggesting that a trade-off relationship 313 between intensity and latency of the PHA response may hold among anurans. In adult anurans, 314 PHA $_{\max }$ may be reached at $12 \mathrm{~h}$ (Clulow, Harris \& Mahony, 2015), $14 \mathrm{~h}$ (Josserand et al., 2015), 31524 h (Brown, Shilton \& Shine, 2011), or 48 h (Clulow, Harris \& Mahony, 2015) after PHA 316 injection. For post-metamorphic amphibians, a range of ecologically meaningful environmental 317 stressors, such as pond desiccation (Gervasi \& Foufopoulos, 2008), different protein 318 concentrations of diets (Venesky et al., 2012), and low and high population density (Clulow, 319 Harris \& Mahony, 2015) have great influences on the inflammation response induced by PHA antigen. Asiatic and Mongolian toads, and Dark-spotted frogs are sympatric common species, but the two formers are terrestrial and disperse slowly, and the latter inhabit lentic ponds and disperse fast by swimming or jumping (Fei et al., 2009a, b). It has been reported that the helminth and parasite infection rates in Dark-spotted frogs and Asiatic toads are $90.38 \%$ and $100 \%$, respectively, and the average intensity of infection is 20.21 and 28.34, respectively in Shanghai (Zhu et al., 2014; Zhao et al., 2014). However, Mongolian toads were not infected by multiple digenetic trematodes from north China ( $\mathrm{Li} \& \mathrm{Gu}$, 1978). PHA-triggered inflammation was similarly impaired by Eimeria sp. infection alone or co-occurring with a number of gastrointestinal nematodes in the subterranean rodent, Ctenomys talarum (Merlo, Cutrera \& 
330 lower peak response than Mongolian toads with a late response (Fig. 3), suggesting that parasite 331 infections may evoke the changes of PHA response patterns. However, in Xenopus laevis, 332 swelling induced by single injection of PHA was not significantly affected by the fungus disease, Batrachochytrium dendrobatidis supernatants, but swelling caused by a secondary injection of PHA was significantly reduced by $B$. dendrobatidis supernatants (Fites et al., 2014). It is noted that the magnitude of $\mathrm{PHA}_{\max }$ was significantly positively correlated with the timing of $\mathrm{PHA}_{\max }$ between data of all individuals from the three anuran species, but not for the data within species, suggesting that the magnitude and timing of $\mathrm{PHA}_{\max }$ is species-specific.

Overall, we found that immune responsiveness to PHA did not differ between sexes for any anuran species (Table 2, Fig. 2), but PHA $_{\max }$ and its timing for toads and frogs varied among species (Fig. 3). This scenario allows PHA assay to be applied to a broad range of amphibian species under field conditions, as a simple, inexpensive and effective proxy to quantify and evaluate a facet of immune response. For future ecoimmunological studies of amphibians, PHA assay will play an important role by integrating the changes of other components of immune system facing newly emerging pathogens or environmental factors. Lastly, we caution that it is still necessary to test the validation of PHA assay in advance for a new species by using appropriate internal controls before carrying out studies under specific circumstances.

\section{ACKNOWLEDGEMENTS}

Thanks to Xinxin NIU, Zhenfei XIAN, and Shuli HUANG from Anhui Agricultural University for help in the field.

\section{REFERENCES}

Bílková B, Albrecht T, Chudíčková M, Holáň V, Piálek J., Vinkler M. 2016. Application of Concanavalin A during immune responsiveness skin-swelling tests facilitates measurement interpretation in mammalian ecology. Ecology and Evolution 6: 4551-4564 DOI: 
10.1002/ece3.2211.

Bílková B, Vinklerová J, Vinkler M. 2015. The relationship between health and cell-mediated immunity measured in ecology: Phytohaemagglutinin skin-swelling test mirrors blood cellular composition. Journal of Experimental Zoology Part A: Ecological Genetics and Physiology 323: 767-777 DOI: 10.1002/jez.1990.

Boughton RK, Joop G, Armitage SAO. 2011. Outdoor immunology: methodological considerations for ecologists. Functional Ecology 25: 81-100 DOI: 10.1111/j.13652435.2010.01817.x.

Brock PM, Murdock CC, Martin LB. 2014. The history of ecoimmunology and its integration with disease ecology. Integrative and Comparative Biology 54: 353-362 DOI: 10.1093/icb/icu046.

Brown GP, Phillips BL, Dubey S, Shine R. 2015. Invader immunology: invasion history alters immune system function in cane toads (Rhinella marina) in tropical Australia. Ecology Letters 18: 57-65 DOI: 10.1111/ele.12390.

Brown GP, Shilton CM, Shine R. 2011. Measuring amphibian immunocompetence: validation of the phytohemagglutinin skin-swelling assay in the cane toad, Rhinella marinus. Methods in Ecology and Evolution 2: 341-348 DOI: 10.1111/j.2041-210X.2011.00090.x.

Burnham KP, Anderson DR. 2004. Multimodel inference understanding AIC and BIC in model selection. Sociological Methods and Research 33: 261-304 DOI: 10.1177/0049124104268644.

Cao YP, Bai M, Ma R, Chen HB, Zhang Z, Li Z, Ren SS. 2000. Studies on the ecology and morphological physiology of Rana nigromaculata before and after hibernation. Sichuan Journal of Zoology 19: 159-162 DOI: 10.3969/j.issn.1000-7083.2000.03.019.

Carey C, Cohen N, Rollins-Smith L. 1999. Amphibian declines: an immunological perspective. Developmental and Comparative Immunology 23: 459-472 DOI: 10.1016/S0145$305 X(99) 00028-2$. 
Christe P, Arlettaz R, Vogel P. 2000. Variation in intensity of a parasitic mite (Spinturnix myoti) in relation to the reproductive cycle and immunocompetence of its bat host (Myotis myotis). Ecology Letters 3: 207-212 DOI: 10.1046/j.1461-0248.2000.00142.x.

Clulow S, Harris M, Mahony MJ. 2015. Optimization, validation and efficacy of the phytohaemagglutinin inflammation assay for use in ecoimmunological studies of amphibians. Conservation Physiology 3: DOI: 10.1093/conphys/cov042.

de Bellocq JG, Krasnov BR, Khokhlova IS, Pinshow B. 2006. Temporal dynamics of a T-cell mediated immune responses in desert rodents. Comparative Biochemistry and Physiololgy. A: Molecular and Integrative Physiology 145: 554-559 DOI: 10.1016/j.cbpa.2006.08.045.

Demas GE, Zysling DA, Beechler BR, Muehlenbein MP, French SS. 2011. Beyond phytohaemagglutinin: assessing vertebrate immune function across ecological contexts. Journal of Animal Ecology 80: 710-730. DOI: 10.1111/j.1365-2656.2011.01813.x.

Downs CJ, Adelman JS, Demes GE. 2014. Mechanisms and methods in ecoimmunology: integrating within-organism and between-organism processes. Integrative and Comparative Biology 54: 340-352 DOI: 10.1093/icb/icu082.

Fei L, Hu SQ, Ye CY, Tian WS, Jiang JP, Wu GF, Li J, Wang YS. 2009a. Anura. Amphibian Volume 2. Fauna Sinica. Bei Jing: Science Press. (in Chinese)

Fei L, Hu SQ, Ye CY, Tian WS, Jiang JP, Zhong SX, Li J, Wang YS. 2009b. Anura Ranidae. Amphibian Volume 3. Fauna Sinica. Bei Jing: Science Press. (in Chinese)

Finger JW, Amanda AL, Thomson PC, Shilton CM, Brown GP, Moran C, Miles LG, Glenn TC, Isberg SR. 2013. Using phytohaemagglutinin to determine immune responsiveness in saltwater crocodiles (Crocodylus porosus). Australia Journal of Zoology 61: 301-311 DOI: org/10.1071/ZO13041. 
Fites JS, Reinert LK, Chappell TM, Rollins-Smith L. 2014. Inhibition of local immune responses by the frog-killing fungus Batrachochytrium dendrobatidis. Infection and Immunity 82: 4698-4706 DOI: 10.1128/IAI.02231-14.

Forbes MR, McRuer DL, Shutler D. 2006. White blood cell profiles of breeding American toads (Bufo americanus) relative to sex and body size. Comparative Clinical Pathology 15: 155-159 DOI: 10.1007/s00580-006-0623-5.

Gilbertson MK, Haffner GD, Drouillard KG, Albert A, Dixon B. 2003. Immunosuppression in the northern leopard frog (Rana pipiens) induced by pesticide exposure. Environmental Toxicology and Chemistry 22: 101-110 DOI: 10.1002/etc.5620220113.

Goto N, Kodama H, Okada K, Fujimoto Y. 1978. Suppression of phytohemagglutinin skin response in thymectomized chickens. Poultry Science 57: 246-250 DOI: 10.3382/ps.0570246.

Graham AL, Allen JE, Read AF. 2005. Evolutionary causes and consequences of immunopathology. Annual Review of Ecology Evolution and Systematics 36: 373-397 DOI: 10.1146/annurev.ecolsys.36.102003.152622.

Hawley DM, Altize SM. 2011. Disease ecology meets ecological immunology: understanding the links between organismal immunity and infection dynamics in natural populations. Functional Ecology 25: 48-60 DOI: 10.1111/j.1365-2435.2010.01753.x.

\section{Horrocks NPC, Hegemann A, Ostrowski S, Ndithia H, Shobrak M, Williams JB, Matson} KD, Tieleman BI. 2015. Environmental proxies of antigen exposure explain variation in immune investment better than indices of pace of life. Oecologia 177: 281-290 DOI: 10.1007/s00442-014-3136-y.

HU ZG. 1989. Studies on variance of sexual hormone in blood plasma of Bufo bufo gargarizans before and after hibernation. Journal of Anhui Normal University, 45-51 DOI: 10.14182/cnki.1001-2443.1989.03.007. 
426

427

428

429

430

431

432

433

434

435

436

437

438

439

440

441

442

443

444

445

446

447

448

449

450

HU ZG. 1990. Studies on variance of sexual hormone in blood plasma of Rana nigromaculata during reproduction. Chinese Journal of Zoology 25: 15-18 DOI: 10.13859/j.cjz.1990.03.006.

Ji Q, Li ZY, Yang Y, Zhu JA, Tang JG. 1995. Relationship between some serum hormones and glucose metabolism in Bufo gargarizans during pre-hibernation, hibernation and posthibernation. Chinese Journal of Zoology 30: 19-22 DOI: 10.13859/j.cjz.1995.02.006.

Jin CC, Qu KS, Zhang ZQ. 2014. Sexual and seasonal differences of the relative fatness and organ mass of Pelophylax nigromaculata. Sichuan Journal of Zoology 33: 106-112 DOI: 10.3969/j.issn.1000-7083.2014.01.021.

Jin CC, Zhang ZQ. 2014. Sexual and seasonal differences of digestive tract mass and length in Pelophylax nigromaculata. Chinese Journal of Zoology 49: 207-214 DOI: 10.13859/j.cjz.2014.02.020.

Josserand R, Troïanowski M, Grolet O, Desprat JL, Lengagne T, Mondy N. 2015. A phytohaemagglutinin challenge test to assess immune responsiveness of European tree frog Hyla arborea. Amphibia-Reptili 36: 111-118 DOI: 10.1163/15685381-00002983.

Kennedy MW, Nager RG. 2006. The perils and prospects of using phytohaemagglutinin in evolutionary ecology. Trends in Ecology and Evolution 21: 653-655 DOI:10.1016/j.tree.2006.09.017.

Lee KA, Martin LB, Wikelski MC. 2005. Responding to inflammatory challenges is less costly for a successful avian invader, the house sparrow (Passer domesticus), than its less-invasive congener. Oecologia 145: 244-251 DOI: 10.1007/s00442-005-0113-5.

Li MM, Gu CD. 1978. Report of some digenetic trematodes from frogs and toads of China. Acta Zoologica Sinica 24: 163-169.

Littell RC, Pendergast J, Natarajan R. 2000. Modelling covariance structure in the analysis of repeated measures data. Statistics in Medicine 19: 1793-1819 DOI: 10.1002/10970258(20000715)19:13<1793::AID-SIM482>3.0.CO;2-Q. 
451

452

453

454

455

456

457

458

459

Lochmiller RL, Deerenberg C. 2000. Trade-offs in evolutionary immunology: just what is the cost of immunity? Oikos 88: 87-98 DOI: 10.1034/j.1600-0706.2000.880110.x.

Martin LB, Han P, Lewittes J, Kuhlman JR, Klasing KC, Wikelski M. 2006. Phytohemagglutinin-induced skin swelling in birds: histological support for a classic immunoecological technique. Functional Ecology 20: 290-299 DOI: 10.1111/j.13652435.2006.01094.x.

Martin LB, Hasselquist D, Wikelski M. 2006. Immune investments are linked to pace of life in house sparrows. Oecologia 147: 565-575 DOI: 10.1007/s00442-005-0314-y.

Martin LB, Weil ZM, Nelson RJ. 2007. Immune defense and reproductive pace of life in Peromyscus mice. Ecology 88: 2516-2528 DOI: 10.1890/07-0060.1.

Merlo JL, Cutrera AP, Luna F, Zenuto RR. 2014. PHA-induced inflammation is not energetically costly in the subterranean rodent Ctenomys talarum (tuco-tucos). Comparative Biochemistry and Physiology. A: Molecular and Integrative Physiology 175: 90-95 DOI: 10.1016/j.cbpa.2014.05.021.

Merlo JL, Cutrera AP, Zenuto RR. 2014. Inflammation in response to phytohemagglutinin injection in the Talas tuco-tuco (Ctenomys talarum): implications for the estimation of immunocompetence in natural populations of wild rodents. Canadian Journal of Zoology 92: 689-697 DOI: 10.1139/cjz-2013-0306.

Merlo JL, Cutrera AP, Zenuto RR. 2015. Parasite infection negatively affects PHA-triggered inflammation in the subterranean rodent Ctenomys talarum. Journal of Experimental Zoology Part A Ecological Genetics and Physiology 325: 132-141 DOI:10.1002/jez.2003.

Moreno J, de León A, Faragallo JA, Moreno E. 1998. Breeding time, health and immune response in the chinstrap penguin Pygoscelis Antarctica. Oecologia 115: 312-319 DOI: $10.1007 / \mathrm{s} 004420050522$. 
Navarro C, Marzal A, de Lope F, Møller AP. 2003. Dynamics of an immune response in house sparrows Passer domesticus in relation to time of day, body condition and blood parasite infection. Oikos 101: 291-298 DOI: 10.1034/j.1600-0706.2003.11663.x.

Nilsson JÅ, Granbom M, Råberg L. 2007. Does the strength of an immune response reflect its energetic cost? Journal of Avian Biology 38: 488-494 DOI: $10.1111 / \mathrm{j} .0908-$ 8857.2007.03919.x.

Ots I, Kerimov AB, Ivankina EV, Ilyina TA, Hõrak P. 2001. Immune challenge affects basal metabolic activity in wintering great tits. Proceedings of the Royal Society B Biological Sciences 268: 1175-1181 DOI: 10.1098/rspb.2001.1636.

Owen JP, Clayton DH. 2007. Where are the parasites in the PHA response? Trends in Ecology and Evolution 22: 228-229 DOI:10.1016/j.tree.2007.02.003.

Previtali MA, Ostfeld RS, Keesing F, Jolles AE, Hanselmann R, Martin LB. 2012. Relationship between pace of life and immune responses in wild rodents. Oikos 121: 14831492 DOI: $10.1111 / \mathrm{j} .1600-0706.2012 .020215 . x$.

Sheldon BC, Verhulst S. 1996. Ecological immunology: costly parasite defences and trade-offs in evolutionary ecology. Trends in Ecology and Evolution 11: 317-321 DOI: 10.1016/01695347(96)10039-2.

Smits JE, Bortolotti GR, Tella JL. 1999. Simplifying the phytohemagglutinin skin-testing technique in studies of avian immunocompetence. Functional Ecology 13: 567-572 DOI: 10.1046/j.1365-2435.1999.00338.x.

Stoehr AM, Kokko H. 2006. Sexual dimorphism in immunocompetence: what does life-history theory predict? Behavioral Ecology, 17: 751-756 DOI: 10.1093/beheco/ark018.

Thomas JR, Woodley SK. 2015. Treatment with corticosterone delays cutaneous wound healing in male and female salamanders. General and Comparative Endocrinology 216: 33-38 DOI: 10.1016/j.ygcen.2015.04.013. 
Turmelle AS, Ellison JA, Mendonc MT, McCracken GF. 2010. Histological assessment of cellular immune response to the phytohemagglutinin skin test in Brazilian free-tailed bats (Tadarida brasiliensis). Journal of Comparative Physiology. B: Biochemical Systemic and Environmental Physiology 180: 1155-1164 DOI: 10.1007/s00360-010-0486-6.

Venesky MD, Wilcoxen TE, Rensel MA, Rollins-Smith L, Kerby JL, Parris MJ. 2012. Dietary protein restriction impairs growth, immunity, and disease resistance in southern leopard frog tadpoles. Oecologia 169: 23-31 DOI: 10.1007/s00442-011-2171-1.

Vinkler M, Albrecht T. 2011. Handling immunocompetence' in ecological studies: do we operate with confused terms? Journal of Avian Biology 42: 490-493 DOI: 10.1111/j.1600048X.2011.05499.x.

Vinkler M, Schnitzer J, Munclinger P, Albrecht T. 2012. Phytohaemagglutinin skin-swelling test in scarlet rosefinch males: low-quality birds respond more strongly. Animal Behaviour 83: 17-23 DOI:10.1016/j.anbehav.2011.10.001.

Wu YL. 1965. Changes of fatness and some internal organ sizes during natural hibernation in Pelophylax nigromaculata. Chinese Journal of Zoology 7: 116-119 DOI: 10.13859/j.cjz.1965.03.012.

Xu DL, Wang DH. 2010. Fasting suppresses T cell-mediated immunity in female Mongolian gerbils (Meriones unguiculatus). Comparative Biochemistry and Physiology. A: Molecular and Integrative Physiology 155: 25-33 DOI: 10.1016/j.cbpa.2009.09.003.

Zhang ZQ, Huang SL, Zhao ZJ. 2015. Response patterns of phytohemagglutinin-induced skin swelling at different reproductive phases in female striped hamster (Cricetulus barabensis). Acta Theriologica Sinica 35: 74-79. (in Chinese)

Zhang ZQ, Qiu FT, Wang DH. 2011. Sex and seasonal differences and energetic cost of phytohemagglutinin responses in wild Mongolian gerbils (Meriones unguiculatus). Acta Theriologica Sinica 31: 284-290. (in Chinese) 
Zhang ZQ, Zhao ZJ. 2015. Correlations between phytohemagglutinin response and leukocyte profile, and bactericidal capacity in a wild rodent. Integrative Zoology 10: 302-310 DOI: 10.1111/1749-4877.12133.

\section{Zhao QP, Dong H, Han HY, Wu YL, Zhu SH, Li LJ, Wu D, Liang ST, Li S, Zhai Q, Yang} SH, Pei EL, Huang B. 2014. A preliminary investigation on the prevalence of parasites in market toads in Shanghai. Chinese Journal of Animal Infectious Diseases 22: 49-53 DOI:10.3969/j.issn.1674-6422.2014.05.008.

Zhou HM. 1996. Correlation analysis on some physiologic constants in Bufo raddei under hibernation. Sichuan Journal of Zoology 15: 162-164 DOI: 10.3969/j.issn.10007083.1996.04.007.

Zhu SH, Dong H, Zhao QP, Wu D, Wu YL, Li LJ, Han HY, Liang ST, Li S, Zhai Q, Yang SH, Pei EL, Huang B. 2014. A preliminary investigation on the prevalence of helminths in frogs at Shanghai farmers' markets. Chinese Journal of Animal Infectious Diseases 22: 5357 DOI: 10.3969/j.issn.1674-6422.2014.06.009.

Zou SC, Zhu WZ, Chen WD, Xie YY, Ding Y, Jia ZC. 1996. Study on relationship among several physiological constants of Bufo gargarizans pre- and post-hibernation. Sichuan Journal of Zoology 15: 156-158 DOI: 10.3969/j.issn.1000-7083.1996.04.005.

Zuk M, McKean KA. 1996. Sex differences in parasite infections: patterns and processes. International Journal of Parasitology 26: 1009-1023 DOI: 10.1016/S0020-7519(96)00086-0. 